\title{
Members of the Month
}

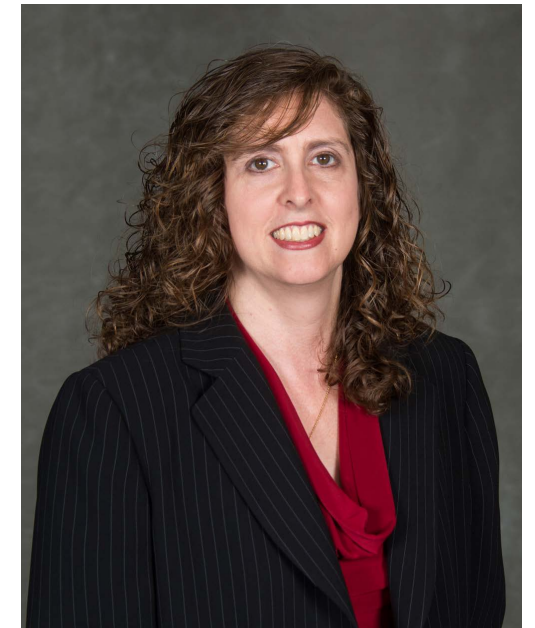

\section{MICHELE SWERS}

NOVEMBER MEMBER OF THE MONTH Georgetown University

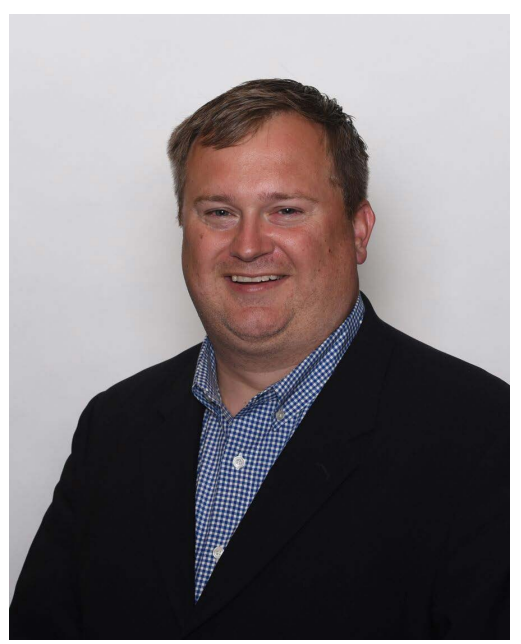

\section{JUSTIN VAUGHN}

JANUARY MEMBER OF THE MONTH Boise State University

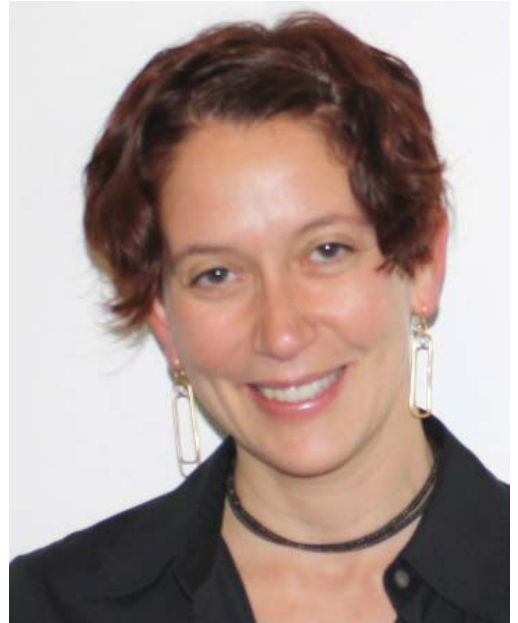

DARA STROLOVITCH DECEMBER MEMBER OF THE MONTH Princeton University

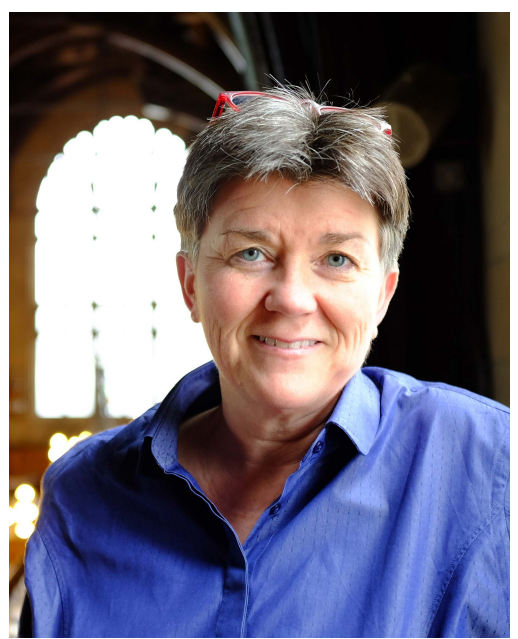

\section{ANGELIA WILSON}

FEBRUARY MEMBER OF THE MONTH University of Manchester

The APSA Member of the Month program recognizes one member each month. Nominations for the award (including self-nominations) may be submitted by members and nonmembers of APSA. To submit your nomination visit our member of the month page online: www.apsanet.org/motm. 